\title{
ANÁLISE DA FUNCIONALIDADE DO PRONAF AGROECOLOGIA EM UMA PROPRIEDADE NA REGIÃO NOROESTE DO RIO GRANDE DO SUL
}

\author{
Anderson Leandro Schneider ${ }^{1}$, Danni Maisa da Silva ${ }^{2}$, Paulo Vanderlei Vargas Groff ${ }^{3}$, Eduardo Lorensi de Souza ${ }^{2}$, \\ Adriana Helena Lau ${ }^{4}$, Maiqueli Patrícia Ehrembrink ${ }^{5}$, Aaron Concha Vasquez Hengles 3 , \\ Diego Armando Amaro da Silva ${ }^{6}$
}

\begin{abstract}
RESUMO - A partir da criação do Programa Nacional de Fortalecimento da Agricultura Familiar - Pronaf Agroecologia abriu-se a oportunidade para que produtores possam financiar o processo de transição ou adequação de suas unidades produtivas às formas agroecológicas de produção. Distante conceitualmente de limitar-se ao aspecto econômico, tampouco excluindo tal critério, a produção agroecológica necessita, com determinada frequência, de aportes financeiros principalmente em sua fase transitória de sistemas convencionais para sistemas agroecológicos. Partindo do princípio da existência de uma modalidade específica para o financiamento da consolidação da Agroecologia no Brasil, o Pronaf Agroecologia, busca-se através deste estudo de caso, compreender aspectos relacionados ao acesso ao crédito do Pronaf Agroecologia e sua importância para os produtores que se utilizam de tal política pública. Para tal, realizou-se um estudo de caso em uma propriedade possuidora de certificação orgânica e tomadora de recursos do Pronaf Agroecologia. Foram analisados aspectos relacionados à acessibilidade de tal política pública, bem como se comparou suas características com as linhas de crédito já existentes e disponíveis ao financiamento dos modelos tradicionais de produção agrícola. Constatou-se grande similaridade do modelo de financiamento agroecológico com as modalidades tradicionais do Pronaf. Mudanças nos prazos e metodologias de trabalho serão necessários para concretizar esta ferramenta de financiamento dos projetos agroecológicos.
\end{abstract}

Palavras chave: agricultura familiar, crédito rural, política pública.

\section{ANALYSIS OF FUNCTIONALITY OF PRONAF AGROECOLOGY IN A PROPERTY OF THE NORWEST REGION OF RIO GRANDE DO SUL}

\begin{abstract}
From the creation of National Program for Strengthening Family Farming - Pronaf Agroecology the opportunity opened up for producers to finance the process of transition or adaptation of their production units to agroecological forms of production. Conceptually far from being limited to the economic aspect, nor excluding this criterion, agroecological production often requires financial contributions mainly in its transitional phase from conventional systems to agroecological systems. Based on the principle of the existence of a specific modality for financing the consolidation of Agroecology in Brazil, Pronaf Agroecology seeks, through this case study, to understand aspects related to access to credit from Pronaf Agroecology
\end{abstract}

\footnotetext{
${ }^{1}$ Especialista em Segurança Alimentar e Agroecologia. Universidade Estadual do Rio Grande do Sul - UERGS, Unidade em Três Passos. Rua Cipriano Barata, 211 - Bairro Érico Veríssimo - Três Passos/RS. CEP: 98600-000. Telefone (55) $3522-2895$. E-mail: andersonlschneider@hotmail.com

${ }^{2}$ Docente da UERGS, Unidade em Três Passos. E-mails: danni-silva@uergs.edu.br; eduardo-souza@uergs.edu.br

${ }^{3}$ Docente da UERGS, Unidade em Frederico Westphalen. Rua Nossa Sra. Aparecida, 115 - Bairro Aparecida, Frederico Westphalen/RS. CEP: 98400-000. Telefone (55) 3744-1142. E-mails: paulo-groff@uergs.edu.br; aaron-hengles@uergs.edu.br

${ }^{4}$ Docente da UERGS, Unidade Hortências. Rua Assis Brasil, 842. Bairro Centro, São Francisco de Paula/RS. CEP: 95.400-000. Telefone (54) 3244-2912. E-mail: adriana-lau@uergs.edu.br

${ }^{5}$ Acadêmica do Curso de Bacharelado em Agronomia. UERGS. Unidade em Três Passos. E-mail: maiqueli.p@hotmail.com

${ }^{6}$ Mestre em Agricultura e Ambiente. Especialista em Segurança Alimentar e Agroecologia. UERGS, Unidade em Três Passos. E-mail: damaro.agro@gmail.com
} 
and its importance for producers who use such public policy. To this end, a case study was carried out on a property with organic certification and borrower of resources from Pronaf Agroecologia. Aspects related to the accessibility of such public policy were analyzed, as well as its characteristics were compared with the existing credit lines available for financing traditional models of agricultural production. There was a great similarity between the agroecological financing model and the traditional modalities of Pronaf. Changes in deadlines and work methodologies will be necessary to make this financing tool for agroecological projects a reality.

Keywords: family farming, public policy, rural credit.

\section{INTRODUÇÃO}

Contemplados e reconhecidos pela participação no cenário econômico, os agricultores familiares passaram, a partir das últimas décadas, por um processo de valorização e reconhecimento de sua importância em várias dimensões: cultural, social, econômica e ambiental. Durante o período da chamada modernização conservadora, o crédito subsidiado privilegiava a agricultura patronal e as regiões mais ricas, enquanto a agricultura familiar era colocada em segundo plano. Desta forma, o Pronaf surgiu, em meados da década de 1990, para suprir a ausência de uma política pública específica para a agricultura familiar (Souza et al., 2011). Através da mobilização social da classe rural dos pequenos produtores, praticamente desassistida até então por programas governamentais de incentivo e fomento conquista em 1995, a criação do Programa Nacional de Fortalecimento da Agricultura (Pronaf), como uma importante ação que desencadeou a emergência de outras políticas diferenciadas para o setor (Grisa \& Schneider, 2014).

Através da criação do Pronaf, novas linhas de crédito passaram a ser operacionalizadas pelos agentes participantes do Sistema Nacional de Crédito Rural (SNCR). De acordo com Gazolla \& Schneider (2013) o surgimento do Pronaf na década de 1990, consiste na política preponderante de fomento econômico e produtivo para a agricultura familiar através da qual surgem outros importantes programas e políticas para este setor social. A ingerência do estado brasileiro na agricultura, por intermédio da criação do Pronaf, exprime a inclusão legítima da agricultura familiar às políticas para o espaço rural (Mattei, 2010; Gazolla \& Schneider, 2013). Anjos et al. (2004) afirmam que a criação do Pronaf no ano de 1995 constitui-se como um marco na interferência do país no meio rural brasileiro, fruto das pressões sindicais e de movimentos sociais em busca de melhores condições de permanência no meio rural (Sambuichi \& Oliveira, 2011). Para De Conti \& Roitman (2011), o fato de criar linhas específicas dentro do programa, tais como Agroecologia, Mais Alimentos e Agroindústria, proporcionou a expansão do Pronaf.
Segundo Gazzola \& Schneider (2013), o Pronaf proporcionou o fortalecimento da inserção produtiva histórica da agricultura familiar no qual se destacam o cultivo de milho e soja, o que acarreta em um processo de especialização produtiva com consequente vulnerabilidade social das famílias e a mercantilização social e econômica. Criado a partir de ideologias de diversificação produtiva na agricultura familiar, o Pronaf vem se consolidando ainda mais um modelo de desenvolvimento pautado no uso intensivo de insumos, aumento da produtividade e na especialização produtiva, gerando problemas ambientais e sociais (Sambuichi \& Oliveira, 2011). Aliado ao Pronaf, em 2012 foi instituída a Política Nacional de Agroecologia e Produção Orgânica (Pnapo), por meio do Decreto n ${ }^{\circ}$ 7.794, de 20 de agosto de 2012, com objetivo de integrar, articular e adequar políticas, programas e ações indutoras da transição agroecológica e da produção orgânica e de base agroecológica (Brasil, 2012). Logo após, para execução da Pnapo, cria-se o Plano Nacional de Agroecologia e Produção Orgânica (Planapo), que também se caracteriza como uma política pública do Governo Federal para ampliar e efetivar ações para o desenvolvimento rural sustentável.

Nesse sentido, no Plano Safra da Agricultura Familiar 2014/2015 o Pronaf se constituiu na principal política agrícola para a agricultura familiar (em número de beneficiários, capilaridade nacional e recursos aplicados) chegando ao valor de R\$24,1 bilhões (Grisa \& Schneider, 2014). Em 2015 o Pronaf contou com R\$ 21,8 bilhões, se destacando pelo número de beneficiários e pela capilaridade nacional. De acordo com a matriz de dados do crédito rural, disponibilizada pelo Banco Central do Brasil, o RS é o estado com a maior volume de crédito, em 2015, os agricultores familiares gaúchos obtiveram R\$ 5,2 bilhões ( $24,1 \%$ do total). No RS, as atividades agrícolas utilizam três quartos desse valor e o restante é destinado à pecuária. $\mathrm{O}$ número de contratos firmados no último ano com o custeio das atividades foi superior a $237 \mathrm{mil}(83,7 \%$ do total). Atualmente, o Pronaf é dividido em 14 linhas de crédito (subprogramas) e em 2015, os subprogramas mais buscados pelos agricultores gaúchos foram os de custeio 
(R\$ 2,4 bilhões); mais alimentos (R\$ 624,2 milhões); agroindústria-custeio ( $\mathrm{R} \$ 265,3$ milhões) e agroindústriainvestimento ( $\mathrm{R} \$ 98,3$ milhões).

Dentre as modalidades de crédito passíveis de acesso por parte dos agricultores enquadrados no Pronaf, encontra-se uma direcionada especificamente ao financiamento de atividades agroecológicas: Pronaf Agroecologia. Segundo Brasil (2016) o PronafAgroecologia é uma linha para financiamento de investimentos dos sistemas de produção de produtos agroecológicos ou orgânicos, incluindo os custos de implantação e manutenção dos sistemas. Dentre os estados brasileiros, o Rio Grande do Sul (RS) foi o estado brasileiro que concentrou os contratos do Pronaf (Deser, 2007), pois do total de recursos aplicados no Pronaf em todo o país, o Rio Grande do Sul é responsável por $20 \%$ dos recursos e $15 \%$ dos contratos, o que demonstra a importância do crédito rural para a agricultura gaúcha (Emater/RS-Ascar, 2020).

Do total, 1,47 milhões de reais se destinaram ao Pronaf agroecologia em 2015 (Banco Central do Brasil, 2016), deixando claro que os agricultores gaúchos têm buscado esse acesso à essa linha específica do Pronaf.

Quando se busca compreender o elemento crédito e sua relação com a agricultura familiar, é valiosa uma análise de suas características de acessibilidade por este público. Considerando-se as peculiaridades deste tipo de financiamento, neste trabalho objetivou-se, através de um estudo de caso, compreender aspectos relacionados ao acesso ao crédito do Pronaf Agroecologia e sua importância para os produtores que se utilizam de tal política pública.

\section{METODOLOGIA}

A pesquisa sobre o Ponaf Agroecologia em uma propriedade rural na localidade de Lajeado Fazenda, no município de Crissiumal, localizado no noroeste do Estado do Rio Grande do Sul foi desenvolvida através do método monográfico, conforme descrito por Antônio Carlos Gil (2008). O estudo de caso realizado em profundidade é representativo de outros semelhantes (Gil, 2008), no qual a unidade produtiva de agricultura familiar em tela acessou os recursos do programa de financiamento do governo. A propriedade rural foi escolhida pela acessibilidade e por ter solicitado o financiamento pelo Pronaf Agroecologia, o que não é comum na região deste estudo.

Para analisar a situação foi realizada a pesquisa de cunho exploratório, com a finalidade de desenvolver e esclarecer os conceitos e ideias aplicáveis ao estudo de caso de tema incipientemente explorado. Foram necessários seu esclarecimento e delimitação, o que exigiu revisão da literatura, discussão com especialistas e outros procedimentos, conforme recomendações de Gil (2008). $\mathrm{Na}$ revisão bibliográfica foram usados como principais descritores 'políticas públicas para agricultura familiar', 'financiamento para agricultura familiar', 'crédito rural', 'Pronaf Agroecologia' pesquisados nos index Portal de Periódicos CAPES, Scielo Brasil e Google Acadêmico. Na pesquisa documental foram usados relatórios do Ministério do Desenvolvimento Agrário (MDA). Discussão com especialistas deu-se no âmbito da EMATER/RS e MDA, através informações pessoais, entrevistas por telefone e e-mail.

Os procedimentos técnicos realizados foram entrevistas e pesquisa de campo. Para a coleta de dados qualitativos foi realizada primeiramente uma entrevista semiestruturada com toda a família, que caracteriza a principal mão-de-obra da propriedade. Assim foi possível formular perguntas específicas, respondidas pelo produtor rural em entrevista estruturada, como contratante do Pronaf Agroecologia. A pesquisa de campo ocorreu através de visita técnica à propriedade rural, para observação do ambiente e manejos produtivos. Os métodos foram aplicados conforme orientações do Manual de Metodologia da Emater/RS-Ascar (Lopes, 2016).

A análise da política de incentivo à produção de base agroecológica ocorreu por meio das respostas fornecidas pelo produtor responsável pela contratação da operação de crédito e de observações acerca dos resultados obtidos em relação à melhoria nas condições socioeconômicas e ambientais da propriedade visitada, com base nas teorias existentes relativas ao objeto de estudo. De igual forma, todos os aspectos relacionados à acessibilidade e funcionalidades do programa Pronaf Agroecologia foram analisados visando à compreensão da efetividade ou não de tal política pública em comparação com as modalidades tradicionais de financiamento.

\section{RESULTADOS E DISCUSSÃO}

\section{O Pronaf agroecologia}

A consolidação do Pronaf é visível a partir da análise da ascensão de seus números e valores acessados. Para dar aporte e sustentação ao volume considerável de recursos disponibilizados entre todas as suas linhas disponíveis, o programa se utiliza de fontes tanto públicas, quanto privadas. Compõem as fontes públicas, diversos fundos e os recursos orçamentários, cada qual com organização e procedimentos de decisão próprios 
em relação à destinação dos recursos. As fontes privadas provêm da captação de recursos por instituições financeiras com caráter compulsório de destinação ao crédito rural, sendo optativa a destinação ao Pronaf. Dentre tais fontes públicas e privadas citam-se o Fundo de Amparo ao Trabalhador (FAT), Poupança Rural, Banco Nacional de Desenvolvimento Econômico e Social (BNDES), Fundos Constitucionais, Orçamento Geral da União (OGU) e recursos provenientes de bancos cooperativos. Devido a esta diversidade de fontes pressupõe-se certa instabilidade na disponibilidade de recursos (De Conti \& Roitmann, 2011; Schneider, 2004).

No que se refere às taxas de juros praticadas no âmbito do Pronaf, estas vieram, ao longo dos anos, passando por sucessivas reduções. Chegaram atualmente a patamares bem abaixo das taxas básicas praticadas no mercado financeiro. Sobre operações de investimento, como no caso específico de análise do presente trabalho, podem incidir taxas de juros anuais de $1 \%$ (um por cento). Como visto anteriormente, uma parte dos recursos do Pronaf é proveniente de fontes privadas. Os meios de captação utilizados pelas instituições financeiras privadas possuem custos geralmente maiores que a rentabilidade proporcionada pelos empréstimos no âmbito do Pronaf. Desta forma, a destinação de tais recursos para o Pronaf só é possível através da participação do Tesouro Nacional, assumindo os custos necessários à cobertura da diferença entre as taxas. Tal mecanismo recebe o nome de equalização de recursos financeiros (De Conti \& Roitmann, 2011). Essa mesma equalização dos recursos financeiros cobre despesas administrativas e avaliza parte das operações de crédito, cobrindo os riscos a que está sujeito o sistema bancário (Schneider, 2004).

De acordo com Brasil (2014), o Pronaf Agroecologia destina-se ao financiamento de empreendimentos de base agroecológica e que se enquadram em alguns critérios, dentre os quais: I - sistemas de produção de base agroecológica, ou em transição para sistemas de base agroecológica, conforme normas estabelecidas pela Secretaria da Agricultura Familiar (SAF) do Ministério do Desenvolvimento Agrário (MDA); II - sistemas orgânicos de produção, conforme normas estabelecidas pelo Ministério da Agricultura, Pecuária e Abastecimento (Mapa). Tais critérios estão de acordo com a finalidade de incremento do financiamento para os sistemas de base agroecológica ou orgânicos, incluindose os custos relativos à implantação e manutenção dos empreendimentos que optam por modos de produção sustentáveis.
Tendo como argumento a singularidade do Pronaf Agroecologia no que diz respeito ao financiamento da Agroecologia no Brasil, entende-se de fundamental importância a existência de tal política para a consolidação dos empreendimentos agroecológicos conclusos ou em fase de transição. Para Lima (2017) é importante reconhecer que existe o incentivo advindo de políticas públicas voltadas aos agricultores familiares, como o Pronaf Agroecologia, orientado para o financiamento de projetos de investimento de sistemas de produção agroecológicos ou orgânicos, que, em conjunto com outras políticas públicas, podem contribuir para que, cada vez mais agricultores familiares criem estratégias e participem de experiências de desenvolvimento rural pautadas nos princípios da Agroecologia. Deste modo julga-se relevante uma análise de tal política pública para a compreensão de sua funcionalidade, acessibilidade e efetividade de seus propósitos.

A despeito da importância da existência de um acompanhamento da situação das iniciativas em prol da Agroecologia no Brasil, os dados disponíveis ainda são incipientes para efeitos estatísticos e da pesquisa em geral. As informações disponíveis referentes ao Pronaf encontramse disponíveis, dentre outros locais, nos sítios do MDA e do Banco Central do Brasil (Bacen). No entanto, as informações disponíveis em ambos os órgãos governamentais, referemse aos números totais de financiamento pelo Pronaf, sem acesso a dados específicos. Segundo informações do próprio MDA, a forma como as informações são geradas no atual sistema de registro de operações do crédito rural brasileiro, não permitem a pesquisa documental de dados categorizados por modalidades de investimento. Esse sistema de armazenamento das informações do crédito agrícola, o chamado Sistema Comum de Operações Rurais (SICOR), guarda e permite o acesso aos dados do crédito rural brasileiro sem, no entanto, permitir o reconhecimento dos aportes oriundos do Pronaf Agroecologia.

Apesar da aparente lógica que conecta, de um lado, a demanda por crédito específico para a implantação, transição ou melhoria de sistemas agroecológicos e, de outro, a existência de uma política governamental direcionada ao suprimento de tal necessidade financeira, através da pesquisa bibliográfica, documental e informações obtidas a campo, ainda é inexpressivo o número de contratos firmados na modalidade Pronaf Agroecologia no Brasil, em comparação com as demais linhas disponibilizadas pelo Pronaf. Isso explica o motivo pelo qual decidiu-se por um estudo de caso, já que a propriedade rural em tela foi a única encontrada na região noroeste do estado do RS, que acessou essa modalidade específica de financiamento. 
Em pesquisa realizada com agricultores familiares do município de Pelotas/RS, Finatto \& Salamoni (2008) relatam que apesar de alguns dos pesquisados utilizarem recursos provenientes do Pronaf em sua produção de base agroecológica, nenhum dos financiamentos era da linha do Pronaf Agroecologia. O número incipiente de operações contratadas via Pronaf Agroecologia pode ser atribuído ao desconhecimento, por parte dos agricultores, da existência de tais linhas de crédito e pela falta de interesse por parte dos operadores de crédito por sistemas não convencionais e não rotineiros (Von Der Weid, 2006; Cárdenas, 2013).

Outros motivos que reduzem a procura por este tipo de crédito encontram-se no caráter produtivista vinculado ao Pronaf. Com a imprescindibilidade de colocar em funcionamento o aparato burocrático vinculado à liberação de crédito, os agentes de desenvolvimento obrigam-se a adequar os projetos técnicos aos pacotes tecnológicos altamente dependentes do aporte de insumos (Silva, 2009). Cárdenas (2013) reconhece que a falta de indicadores técnicos capazes de demonstrar o retorno financeiro dos modelos de produção agroecológica dificultam a liberação de recursos por parte das instituições financeiras. Para Fávero (2007), a resistência dos agentes de crédito ao financiamento de sistemas de produção agroecológicos e o direcionamento do Pronaf em financiar equipamentos e insumos específicos, dificulta o acesso ao Pronaf Agroecologia. Borges (2007), classifica o Pronaf Agroecologia como inadequado, devido às exigências de projetos de transição em prazos incompatíveis com os processos de conversão, o que dificulta o acesso dos agricultores a esta linha de crédito.

A falta de reconhecimento dos métodos de manejo agroecológico pelas instituições bancárias, nos primeiros anos de existência do Pronaf, impossibilitava o financiamento dos projetos. Para a concessão de crédito de custeio, os agentes financeiros o condicionavam ao seguimento das recomendações técnicas de pesquisa agrícola, destinados à aquisição de pacotes tecnológicos altamente dependentes do uso de fertilizantes químicos e agrotóxicos (Von Der Weid, 2006). A falta de assistência por técnicos que estejam familiarizados com a elaboração de projetos alinhados com o formato adequado aos modelos agroecológicos também foi apontado como um dos motivos pelo número reduzido de acessos ao Pronaf Agroecologia (Cárdenas, 2013). Gomes (2009) chama atenção para a morosidade nas análises dos projetos por parte dos agentes financeiros, dificultando ainda mais o acesso.

Por se tratar de um modo diferenciado de organização de todos os elementos produtivos envolvidos, a Agroecologia não compartilha das mesmas necessidades de investimento sucessivas percebidas nos modelos convencionais de produção agrícola. De acordo com Von Der Weid, (2007), embora a produção agroecológica necessite menor aporte de insumos químicos e, sob certas circunstâncias, menor utilização de maquinário, em fases transitórias outros investimentos, tal como mãode-obra, se fazem necessários. Em outras situações, não necessariamente em casos de transição agroecológica, a exigência e infraestrutura inicial somada ao estado de descapitalização vivenciado pela agricultura familiar, exige investimentos significativos na quase totalidade das situações (Von Der Weid, 2007). O alto custo do processo de transição agroecológica atribui-se ao avançado grau de degradação em que se encontra a terra. Tal estado de degradação tem origem no uso descontrolado de agroquímicos aliado a técnicas agrícolas tradicionais, em que não há reposição de fertilidade e que levaram ao esgotamento das principais características biológicas da terra (Shiki, 2010).

Partindo-se do princípio da existência de uma modalidade específica para o financiamento da Agroecologia no Brasil buscou-se compreender a essência conjuntural de tal política. Para tal, realizou-se o estudo de caso em uma propriedade possuidora de certificação orgânica e tomadora de recursos do Pronaf Agroecologia. Foram analisados aspectos relacionados à acessibilidade a essa política pública que enfatiza o manejo agroecológico, bem como se comparou suas características com as linhas de crédito similares já existentes no Pronaf, e disponíveis ao financiamento dos modelos tradicionais de produção agrícola.

\section{Estudo de caso}

O objeto do estudo de caso foi uma propriedade rural no interior do município de Crissiumal, no Rio Grande do Sul. A propriedade com área de 37 hectares, sendo $80 \%$ da área total cultivada com cana-de-açúcar caracteriza a agricultura familiar, pela mão-de-obra. Alguns poucos trabalhadores em tempo integral e outros contratados sazonalmente atendem à demanda especial do manejo agroecológico.

Por se tratar de uma propriedade com certificação em produção orgânica, os trabalhos de manejo incluem técnicas como adubação verde, adubação orgânica e rotação de culturas, entre outras. Toda a cana-de-açúcar produzida anualmente destina-se à fabricação de cachaça orgânica tipo exportação. A bebida é produzida em uma agroindústria situada na sede da propriedade e tem como destino a Europa e países da América do Norte, como 
Estados Unidos e Canadá. Tal estabelecimento é certificado pela empresa Ecocert.

A operação de crédito, via Pronaf Agroecologia realizada pela família destinou-se à aquisição de mudas de cana-de-açúcar, adubo orgânico e pagamento de mãode-obra destinada ao plantio e tratos culturais. A liberação do crédito foi realizada por uma Cooperativa de Crédito Rural, do município de Crissiumal. O projeto foi elaborado pela própria cooperativa e os recursos foram oriundos do Banco Nacional de Desenvolvimento Econômico e Social (BNDES).

O valor do financiamento acessado foi de $\mathrm{R} \$$ 49.800,00. A forma de pagamento foi estabelecida para o prazo de dez anos, sendo os três primeiros de carência. Deste modo, durante os três primeiros anos não foram efetuados pagamentos de juros ou do capital. Após o término da carência, ou seja, do quarto ano em diante, o valor do empréstimo foi pago em sete parcelas anuais compostas pela soma do capital, acrescido dos juros, por meio do Sistema de Amortização Constante (SAC), no qual as parcelas são decrescentes.

Após a análise do desenvolvimento de todo o processo de acesso ao crédito, algumas considerações nos remetem à compreensão de situações que, embora sutis em uma primeira análise, são fundamentais, por qualquer que seja seu procedimento interpretativo.

Sob a observação das condições socioambientais da propriedade, na qual se fez a aplicação dos recursos financeiros oriundos do programa Pronaf Agroecologia, destacam-se aspectos que conduzem às reflexões pertinentes. Sobre as condições ambientais, a propriedade já cumpria, mesmo antes do financiamento, os quesitos que lhe concediam o direito à certificação orgânica, atendendo também a critérios que a classificavam como agroecológica. Após a operação de crédito, todos os procedimentos e técnicas de manejo anteriormente praticados mantiveramse. Não houve, portanto, mudanças significativas em qualquer aspecto relacionado à questão ambiental ou de manejo agrícola da propriedade. Tampouco pode-se afirmar que era essa a principal pretensão da operação financeira. Portanto, para a análise da eficácia do projeto em questão, optou-se por avaliar mudanças em aspectos relacionados ao viés econômico e social.

A entrevista estruturada aplicada ao produtor responsável pelo acesso à linha de crédito Pronaf Agroecologia resultou no conhecimento de alguns pontos importantes a serem considerados. Conforme os relatos do produtor em relação à política pública em si, vários aspectos técnicos e procedimentais a tornam similar às modalidades tradicionais de financiamento agrícola, na quase totalidade dos quesitos avaliados. Em relação aos prazos de desembolso e carência, o Pronaf Agroecologia aplica os mesmos critérios adotados pelas modalidades convencionais de investimento. Cita-se como exemplo o Pronaf Mais Alimentos. Na época da liberação do Pronaf Agroecologia analisado neste artigo, as duas linhas de financiamento adotavam os mesmos prazos de carência de até três anos e os iguais dez anos de prazo total de desembolso. Desta forma, tornava-se indiferente a opção pela linha de financiamento Pronaf Agroecologia, visto que tanto esta, quanto a modalidade convencional, Pronaf Mais Alimentos, contemplavam e usufruíam dos mesmos critérios temporais em relação à carência e amortizações. O fato de não haver um prazo de carência compatível com o processo de conversão para a agroecologia foi um dos aspectos mais destacados pelo produtor, que se denominou como agroecológico, e assim o trataremos daqui em diante neste artigo, ao responder às perguntas formuladas na entrevista estruturada.

Condições ainda menos satisfatórias quanto ao Pronaf Agroecologia foram diagnosticadas, quando comparadas com outras duas modalidades de investimento, quanto à sustentabilidade: o Pronaf Floresta e o Pronaf Eco. Quando comparada a modalidade Agroecológica com o Pronaf Floresta para a safra 2014/2015, por exemplo, verificou-se condições diferenciadas nos prazos e taxas de juros. Para o Pronaf Floresta são concedidos prazos de até 20 anos para pagamento, com até 12 anos de carência. O Pronaf Eco possui igualmente até 20 anos para pagamento, mas carência menor, de até 8 anos (BRASIL, 2014).

A análise comparativa focada em critérios tais como taxas de juros praticadas, tanto as respostas do produtor agroecológico na entrevista estruturada, quanto o resultado da pesquisa bibliográfica e documental, nos remetem às mesmas conclusões, de similaridades existentes e compartilhadas entre o Pronaf Agroecologia e os modelos convencionais de crédito. As taxas de juros aplicados em ambas às situações são de $1 \%$ (um por cento) ao ano para valores até $\mathrm{R} \$ 10.000,00$ (dez mil reais) e $2 \%$ (dois por cento) para valores superiores. Tais alíquotas, embora representem condições favoráveis e diferenciadas quando confrontadas com taxas praticadas pelo mercado financeiro, via de regra, tornam dispensável a opção por este ou aquele modo de financiamento, quando analisados sob este aspecto. Caporal (2009) sugere mudanças nas políticas de crédito agrícola, quando propõe o uso de tabelas de regressão e progressão nas taxas de juros, de acordo com as práticas ambientais adotadas. Desta forma, o autor defende juros menores para modelos de produção 
sustentáveis, em uma lógica inversa à que foi utilizada no modelo da Revolução Verde, a partir da década de 60, no Brasil.

No contexto apresentado, o estudo realizado por Silva et al. (2018) mostra que as políticas públicas implementadas nos últimos anos em apoio à agricultura familiar no Brasil têm alcançado importantes avanços. No entanto, neste mesmo artigo, os autores destacam limitações importantes relacionadas especialmente à concessão de crédito e apoio técnico necessário para a promoção de modelos sustentáveis de agricultura. Segundo os autores citados, os principais problemas relacionadaos a estas limitações ocorrem em função de que muitas das medidas adotadas pelos programas de governo apresentados estão ainda alinhadas com os sistemas convencionais de produção agropecuária, que foram adotados durante a modernização da agricultura brasileira, na época da Revolução Verde, e que, em geral, resultam em impactos socioambientais negativos, que se contrapõem aos objetivos do desenvolvimento rural sustentável. Estas constatações obtidas na pesquisa bibliográfica e documental deste estudo de caso, infelizmente, corroboram com a percepção do agricultor agroecológico entrevistado, em relação às dificuldades e limitções do Pronaf Agroecologia.

Outro aspecto crítico analisado foi o número de operações de crédito financiado através do Pronaf
Agroecologia. Embora pareça equivocada uma comparação entre as modalidades tradicionais de financiamento e os recursos derivados da linha agroecológica, já que, como anteriormente mencionado, os dados publicados nos relatórios do SICOR não discriminam os montantes relativos a cada uma das linhas de crédito rural, o estudo de caso aliado à uma abordagem exploratória (ver Metodologia), de acordo com Gil (2008), indica consulta e discussão com especialistas como abordagem metodológica possível, para delimitar com maior precisão a situação estudada. Gil (2008) aborda a oportunidade de pesquisa oferecida por determinadas instituições, que oferecem condições materiais como o uso de documentos, "ou a utilização de instrumental para coleta e análise dos dados" (p. 35). "O que se torna necessário é a suficiente habilidade do pesquisador no sentido de adequar as oportunidades oferecidas a objetivos adequados" (Gil, 2008. p. 36).

A discussão com especialistas e acesso através de informações pessoais, e-mails e entrevistas por telefone foi possível pelo trabalho técnico do primeiro autor deste trabalho em uma cooperativa de crédito rural, oportunidades acessadas para finalidades de conhecimento sobre a realidade dos financiamentos supracitados. A Tabela 1 mostra o número de contratos oriundos de recursos do Pronaf Agroecologia.

Tabela 1 - Número de contratos na modalidade Pronaf Agroecologia nas safras de 2005 a 2012 por regiões brasileiras

\begin{tabular}{lcccccccc}
\hline & \multicolumn{7}{c}{ Anos/Safras } \\
\cline { 2 - 9 } Regiões & $2005 / 06$ & $2006 / 07$ & $2007 / 08$ & $2008 / 09$ & $2009 / 10$ & $2010 / 11$ & $2011 / 12$ & TOTAL \\
\hline Sul & 18 & 78 & 82 & 59 & 11 & 0 & 0 & 248 \\
Sudeste & 5 & 66 & 52 & 15 & 11 & 0 & 0 & 149 \\
Centro-oeste & 13 & 20 & 5 & 16 & 13 & 0 & 0 & 67 \\
Nordeste & 20 & 72 & 48 & 19 & 15 & 2 & 0 & 175 \\
Norte & 3 & 25 & 4 & 284 & 26 & 0 & 0 & 342 \\
Total & 59 & 260 & 191 & 393 & 76 & 2 & 0 & 981 \\
\hline
\end{tabular}

Fonte: Informações pessoais, adaptado de MDA (2014). Dados enviados pelo MDA, por e-mail, relativos às informações enviadas pelas instituições financeiras até o dia 24/09/2014.

Os dados da Tabela 1 mostram a limitação do Pronaf Agroecologia, quanto ao número de contratos, por região do Brasil continental. Em relação ao questionamento referente ao reduzido número de contratos acessados via Pronaf Agroecologia, o produtor entrevistado explicou o fato pela semelhança existente entre as modalidades convencionais do Pronaf e a linha agroecológica, aliado à falta de conhecimento e divulgação por parte das instituições financeiras. 
A partir da análise da propriedade rural no estudo de caso é possível afirmar que a política pública específica destinada ao financiamento da Agroecologia no Brasil não atinge de forma integral aos seus objetivos. A similaridade do Pronaf Agroecologia com outras políticas no que diz respeito a continuidade do padrão produtivista e da falta de sustentabilidade nas ações, faz com que o programa não propicie mudanças estruturais no padrão agrícola construído após a revolução verde. Conclusões semelhantes a que chegaram Caporal \& Petersen (2012) quando atentam para o fato de o Brasil não possuir um projeto que direcione para a implantação de ações que garantam uma forma de desenvolvimento mais sustentável. Os mesmos autores afirmam a existência de políticas públicas no Brasil que seguem o padrão de desenvolvimento pautado na produtividade, seguindo os ditames da Revolução Verde. As linhas de financiamento existentes no Pronaf são, em geral, direcionadas à compra de equipamentos e maquinário, no intuito de modernizar a propriedade. As formas alternativas de financiamento dentre as quais encontra-se o Pronaf Agroecologia, acabam sofrendo uma certa resistência por parte dos agentes financeiros operadores do programa e mesmo após longo tempo de existência permanecem a margem das políticas públicas consolidadas (Caporal \& Petersen, 2012).

A participação e envolvimento das instituições de representatividade social desempenham papel fundamental na concretização das políticas públicas. Podese dizer que ainda há um grande vazio institucional na disseminação do Pronaf Agroecologia. Ainda há carência na oferta de assistência técnica e movimentos do terceiro setor tais como sindicatos, cooperativas ou associações que enraízem os ideais da agroecologia e conduzam os agricultores através das possibilidades de adequação e melhorias de suas condições de trabalho. Esta situação fica evidente a partir das afirmações do próprio produtor entrevistado ao destacar a ausência de assistência técnica e foco das políticas públicas, que acabam por incentivar a agricultura convencional. A importância desta orientação desempenhada pelas instituições é relatada por Ferrari \& Abraão (2007). Os autores citam a experiência vivenciada por um grupo de agricultores da Zona da Mata do estado de Minas Gerais no acesso ao Pronaf Agroecologia a partir da orientação e apoio de sindicatos e uma organização de Assessoria, o Centro de Tecnologias Alternativas (CTA). Este relato demonstra a importância do apoio e da orientação de entidades aos agricultores no acesso ao Pronaf Agroecologia. Neste sentido, Lima (2017) afirma que, paralelamente à promoção de políticas públicas governamentais e ao estímulo à Agroecologia, também é fundamental o apoio de outros atores, como cooperativas, associações, universidades e entidades de assistência técnica e extensão rural, para a superação das limitações em torno das diferentes situações socioeconômicas, produtivas, ambientais e de organização associativa presentes nas estratégias e experiências dos agricultores familiares. Vargas et al. (2011) contribuem com esta linha de raciocínio ao relatar a importância dos órgãos de assistência técnica e extensão rural na popularização das linhas do Pronaf destinadas ao financiamento de projetos de diversificação produtiva, dentre os quais se encaixa o Agroecologia. Costabeber \& Moyano (2000) atribuem às ações coletivas da sociedade a consolidação dos processos de transição agroecológicos.

A legitimidade do Estado como gestor de políticas públicas o coloca no dever de estabelecer diálogos constantes com a sociedade civil na busca por melhorias nas questões relacionadas ao desenvolvimento, tanto do ponto de vista social quanto ambiental e econômico. A difusão do Pronaf Agroecologia no Brasil necessita desta intervenção estatal que, como destaca Assis (2006) desempenha papel fundamental na elaboração de políticas públicas, de forma especial nas áreas do crédito, pesquisa e extensão rural nas esferas municipal, estadual e federal. Caporal (2009) reforça esta afirmação ao condicionar a participação do Estado no processo de transição agroecológica mediante programas, planos e políticas públicas.

Em suas respostas às perguntas formuladas, o produtor agroecológico, como um dos sujeitos desse estudo, enfatiza a falta de pesquisas e, por outro lado, a importância que esta teria na consolidação da Agroecologia. O produtor destacou a necessidade de pesquisas voltadas ao desenvolvimento de equipamentos e técnicas de cultivo específicas à produção orgânica e/ou agroecológica, bem como a limitação determinada pela falta de incentivo à comercialização em cadeias curtas (Schneider \& Ferrari, 2015) e certificação da propriedade rural (Emater/RS-Ascar, 2013), que resultariam em menor custo para consumidores e o produtor.

Torna-se imperativo destacar o cenário elucidado pela família de agricultores da realidade vivenciada na propriedade estudada. A lucidez do produtor agroecológico nas suas respostas sobre as perguntas formuladas pelo pesquisador, infelizmente evidenciou, com a corroboração da pesquisa bibliográfica e documental, a pouca eficácia das políticas públicas de incentivo à produção agroecológica. As políticas públicas existem, como pode ser verificado no Plano Nacional de Agroecologia e Produção Orgânica - Planapo (2013), que foi criado para a implementação de 
programas e ações indutoras da transição agroecológica, da produção orgânica e de base agroecológica, "possibilitando à população a melhoria de qualidade de vida por meio da oferta e consumo de alimentos saudáveis e do uso sustentável dos recursos naturais" (p.11), como instrumento de operacionalização, monitoramento, avaliação e controle social das ações organizadas.

Para tornar factível um projeto que possibilite resultados mais positivos no campo agroecológico brasileiro, mudanças em vários quesitos do Pronaf Agroecologia se fazem necessárias. Os processos de conversão nos sistemas produtivos exigem prazos maiores, tanto de carência, quanto para o pagamento do financiamento. Melhorias nas condições apontadas no presente estudo qualificariam o programa agroecológico de financiamento em busca de maior eficácia de seus propósitos e possivelmente fortaleceriam o cenário da Agroecologia no Brasil. A criação do Pronaf Agroecologia representa um avanço na construção de um projeto, porém necessita maior envolvimento das entidades relacionadas abrangendo a assistência técnica, a extensão rural, juntamente com órgãos de representatividade da classe dos agricultores, passando pelos agentes operadores de crédito, classes de representação social em consonância com a participação popular e poder público para desempenhar de modo mais eficaz a disseminação da política de apoio aos produtores de base agroecológica, para o avanço da Agroecologia no Brasil.

\section{CONSIDERAÇÕES FINAIS}

Concluindo o presente estudo, considera-se o Pronaf Agroecologia pouco eficiente em termos práticos, no que se refere ao estudo de caso analisado. A proximidade de características o torna demasiado semelhante aos mecanismos tradicionais de financiamento do Pronaf. Para a propriedade analisada houve pouco acréscimo de situações que viessem a trazer resultados em prol do incentivo à Agroecologia. Esperava-se maiores benefícios de uma linha de crédito criada especificamente para atender às demandas dos agricultores em processo de conversão, ou mesmo para os que já passaram desta fase transitória, para consolidação do modelo agroecológico de produção.

Por se tratar de uma ferramenta relativamente recente na realidade brasileira, o Pronaf Agroecologia carece de ajustes em vários aspectos. Não se pode ignorar a importância desta política pública, que pode ser considerada um avanço no atendimento às reivindicações de vários movimentos sociais por um mecanismo facilitador na busca pela consolidação da Agroecologia como sistema produtivo.

A melhoria de algumas das características do Pronaf Agroecologia, principalmente no que se refere aos prazos, o tornariam mais engajado com a realidade vivenciada nos processos agroecológicos de conversão e/ou para o sucesso daqueles já consolidados. Mudanças na forma de atuação dos agentes operadores do crédito também se fazem necessárias para que o acesso ao Pronaf Agroecologia seja mais frequentemente acessado como política pública e atinja um maior número de beneficiários.

\section{LITERTURA CITADA}

ANJOS, F.S.; GODOY, W.I.; CALDAS, N.V.; GOMES, M.C. Agricultura familiar e políticas públicas: impacto do Pronaf no Rio Grande do Sul. Revista de Economia e Sociologia Rural. Rio de Janeiro, v.42, n.3, p.529-548, 2004.

ASSIS, R.L. Desenvolvimento rural sustentável no Brasil: perspectivas a partir da integração de ações públicas e privadas com base na agroecologia, Ribeirão Preto. Economia Aplicada, v.10, n.1, p.75-89, 2006.

BANCO CENTRAL DO BRASIL (BCB). Matriz de Dados do Crédito Rural. Brasília, DF, 2016. Acessado em: 29 jun. 2020).

BRASIL. Banco Central do Brasil. Manual de Crédito Rural - MCR. Disponível em: <http://www3.bcb.gov.br/ mcr/>. Acesso em: 10 jul. 2014.

BRASIL. Decreto No 7.794, de 20 de agosto de 2012. Institui a Política Nacional de Agroecologia e Produção Orgânica. Diário Oficial [da] República Federativa do Brasil, Poder Executivo, Brasília, DF, 2012. Disponível em: http://www. planalto.gov. br/ccivil_03/_ato2011- 2014/2012/decreto/ d7794.htm. Acesso em: 28 jun. 2020.

BRASIL. Ministério do Desenvolvimento Agrário. Cartilha Plano Safra da Agricultura Familiar 2013/2014. 2013. Disponível em: https://www.yumpu.com/pt/document/ $\mathrm{read} / 39620219 /$ cartilha-plano-safra-2013-2014-cpra.

BRASIL, 2014. Ministério do Desenvolvimento Agrário. Condições do Crédito Rural - Plano de Safra 2014/2015. Disponível em: <http://www.mda.gov.br/sitemda/ sites/sitemda/files/user_img_19/Condições\%20do\%20 Crédito\%202014-2015.pdf>. Acesso em: 22 set. 2014.

BRASIL, 2016. Ministério de Desenvolvimento Agrário MDA. Linhas de crédito: conheça as linhas de crédito do Pronaf. Disponível em: http://www.mda.gov.br/sitemda/ 
secretaria/saf-creditorural/linhasde-cr\%C3\%A9dito. Acesso em: 28 jun. 2020.

BORGES, J.L. A transição do MST para a agroecologia. 2007. Dissertação (Mestrado em Ciências Sociais). Londrina, PR: UEL, 2007. 164p.

CÂMARA INTERMINISTERIAL DE AGROECOLOGIA E PRODUÇÃO ORGÂNICA - CIAPO. Plano Nacional de Agroecologia e Produção Orgânica - PLANAPO. Brasília, DF: MDS, CIAPO, 2013. Disponível em: http://www. agroecologia.gov.br/plano. Acesso em: 29 de jun. 2020.

CAPORAL, F.R. Em defesa de um plano nacional de transição agroecológica: compromisso com as atuais e nosso legado para as futuras gerações. Brasília: Francisco Roberto Caporal, 2008. 35p.

CAPORAL, F.R.; PETERSEN, P. Agroecologia e políticas públicas na América Latina: o caso do Brasil. Agroecologia, n.6, p.63-74, 2012.

CÁRDENAS, R.R. Identificação e avaliação de mecanismos financeiros de suporte em processos de adaptação/mitigação às mudanças climáticas na cafeicultura familiar - O caso de Minas Gerais (Brasil). 2013. Disponível em: <http:// www.coffeeandclimate.org/findings.html?file=tl_files/ CoffeeAndClimate/Brazil/findings\%20Brazil/Cardenas Sumario $\% 20$ Executivo $\% 3$ A $\% 20$ Identificacao $\% 20 \mathrm{e} \% 2 \overline{0}$ avaliacao $\% 20 \mathrm{de} \% 20$ mecanismos $\% 20$ financeiros_PORT. pdf $>$. Acesso em: 23 jul. 2014.

COSTABEBER, J.A.; MOYANO ESTRADA, E. Transição agroecológica e ação social coletiva. Agroecologia $e$ Desenvolvimento Rural Sustentável, v.1, n.4, p.50-60, 2000.

DE CONTI, B.M.; ROITMAN, F.B. Pronaf: uma análise da evolução das fontes de recursos utilizadas no programa. Revista do BNDES, v.35, p.131-168, 2011.

DEPARTAMENTO DE ESTUDOS SÓCIOECONÔMICOS RURAIS (DESER). 2007. Cartilha do PRONAF. Curitiba, Editora da UFPR. 25p.

EMATER/RS-ASCAR. Crédito rural. 2020. Disponível em: Http://www.emater.tche.br/site/area-tecnica/apoioa-gestao-e-producao/credito-rural.php\#.XvpDTShKhPY. Acesso em: 28 jun.2020.

EMATER/RS/ASCAR. Trabalho com produção $e$ certificação orgânica é fortalecido no Noroeste gaúcho. $A$ aliança entre diferentes instituições tem fortalecido a produção e a certificação orgânica nas regiões Fronteira Noroeste e Missões. Assessoria de Imprensa da Emater/ RS-Ascar, 2013. Disponível em: https:/www.agroolhar. com.br/noticias/exibir.asp?id=12247\&noticia=trabalho- com-producao-e-certificacao-organica-e-fortalecido-nonoroeste-gaucho. Acesso em: 29 jun. 2020.

FÁVERO, C. Elaboração participativa do plano safra do território da Serra do Brigadeiro, Minas Gerais. Cadernos de Agroecologia, v.2, n.2, 2007.

FEIX, R.D.; LEUSIN JÚNIOR, S.; AGRANONIK; C. Painel do agronegócio no Rio Grande do Sul - 2016. Porto Alegre: FEE, 2016. 53p.

FERRARI, E.A.; ABRAÃO, S.S. PRONAF Agroecologia: sistematização de uma experiência desenvolvida na Zona da Mata de Minas Gerais. 2007. Disponível em: https:// ctazm.org.br/bibliotecas/pronaf-agroecologia-67.pdf.

FINATTO, R.A.; SALAMONI, G. Agricultura familiar e agroecologia: perfil da produção de base agroecológica do município de Pelotas/RS. Sociedade \& Natureza. v.20, n.2, p.199-217, 2008.

GAZOLLA, M.; SCHNEIDER, S. Qual "Fortalecimento" da Agricultura Familiar? Uma análise do Pronaf crédito de custeio e investimento no Rio Grande do Sul. Revista de Economia e Sociologia Rural. Piracicaba-SP, v.51, n.1, p.45-68, 2013.

GIL, A.C. Métodos e técnicas de pesquisa social. $6^{\mathrm{a}}$ ed. São Paulo: Atlas, 2008. 200p.

GOMES, F.L. Extensão em Agroecologia: Redesenhando sistemas de produção de hortaliças no Agreste Alagoano. Revista Brasileira de Agroecologia, v.4, n.2, 2009.

GRISA, C; SCHNEIDER, S. Três Gerações de Políticas Públicas para a Agricultura Familiar e Formas de Interação entre Sociedade e Estado no Brasil. Revista de Economia e Sociologia Rural. Piracicaba-SP, v.52, Supl. 1, p.S125-S146, 2014.

LIMA, F.A.X. Políticas públicas de ATER e agroecologia: uma análise comparada no estado de Pernambuco. Revista de Extensão e Estudos Rurais, v.6, n.1, jan./jun., 2017.

LOPES, E.B. Manual de metodologia. $1^{\mathrm{a}}$ ed. Curitiba: Gráfica Instituto EMATER, 2016. 180p.

MATTEI, L. Análise da produção acadêmica sobre o Programa Nacional de Fortalecimento da Agricultura Familiar (PRONAF) entre 1996 e 2006. Estudos Sociedade e Agricultura. Rio de Janeiro, v.18, n.1, p.56-97, 2010

SAMBUICHI, R.H.R.; OLIVEIRA, M.A.C. Análise das linhas de crédito do PRONAF para o desenvolvimento sustentável da agricultura familiar. Cadernos de Agroecologia, v.6, n.2, 2011. 
SHNEIDER, S. A abordagemterritorialdodesenvolvimento rural e suas articulações externas. Sociologias, ano 6, n. 11, p. 88-125, 2004.

SCHNEIDER, S.; FERRARI, D.L. Cadeias curtas, cooperação e produtos de qualidade na agricultura familiar: o Processo de Relocalização da Produção Agroalimentar em Santa Catarina. Organizações Rurais \& Agroindustriais, v.17, n.1, p.56-71, 2015.

SHIKI, S. Política agrária e conservação da biodiversidade no Brasil. Estudos Sociedade e Agricultura. Rio de Janeiro v.18, n.2, p.288-316, 2010.

SILVA, F.C.; SANT’ANA, A.L.; MAIA, A.H. Public policy on the family farming sector in Brazil: Towards a model of sustainable agriculture. African Journal of Agricultural Research, v.13, n.33, p.1719-1729, Aug. 2018.

SILVA, L.M.S.; MARTINS, S.R. Impactos das limitações epistêmicas sobre sustentabilidade nas ações do Pronaf na porção sudeste do Pará. Agricultura Familiar. Belém, v.5/8, p.7-28, 2005/2008.

SOUZA, P.M.; NEY, M.G.; PONCIANO, N.J. Evolução da distribuição dos financiamentos do PRONAF entre as unidades da federação, no período de 1999 a 2009. Rio de Janeiro. Revista Brasileira de Economia, v.65, n.3, p.303313, 2011.

VARGAS, D.L.; DORNELES, M.A.R.; HILLIG, C. 10913A retórica de diversificação e sustentabilidade e o viés produtivista do Pronaf em Cachoeira do Sul/RS. Cadernos de Agroecologia, v.6, n.2, 2011.

VON DER WEID, J.M. A transição agroecológica das políticas de crédito voltadas para a agricultura familiar. Revista Agriculturas, v.3, n.1, abr., 2006.

VON DER WEID, J.M. Financiamento da Transição Agroecológica. Caderno do II Encontro Nacional de Agroecologia. Pará-PA, 2007. 104p.

Recebido para publicação em 10/11/2019, aprovado em 29/06/2020 e publicado 30/07/2020. 